\title{
1 Crisis Translation: Considering Language Needs in Multilingual 2 Disaster Settings
}

\section{Abstract}

4 Purpose: The purpose of this conceptual paper is to highlight the role that language

5 translation can play in disaster prevention and management and to make the case for

6 increased attention to language translation in crisis communication.

7 Approach: The article draws on literature relating to disaster management to suggest

8 that translation is a perennial issue in crisis communication.

9 Findings: Although communication with multicultural and multilinguistic communities

10 is seen as being in urgent need of attention, we find that the role of translation in

11 enabling this is underestimated, if not unrecognised.

12 Value: This article raises awareness of the need for urgent attention to be given by

13 scholars and practitioners to the role of translation in crisis communication.

14 Keywords: crisis communication; translation and interpreting; emergency response;

15 cross-cultural barriers; linguistic vulnerability

\section{Introduction}

18 Much as the world is interconnected and globalized in terms of communication, the

19 breadth of social and economic impact of communication in multilingual, transborder as

20 well as national crises remains understudied (Federici, 2016). Long-lasting crises can

21 erupt within multicultural cities (e.g. the 2017 Grenfell Tower fire in London), a region

22 (the 2017 earthquake in Mexico), a nation (the 2011 Great East Japan earthquake, or the

232010 Haiti earthquake), or across borders between multiple countries (the 2004 Boxing

24 Day Tsunami across 18 countries in the Indian Ocean). Triggered by natural hazards, or 
teleological motivations - human-driven disasters, including terrorism and conflict

26 (Glade and Alexander, 2016) - happen within multilingual and multicultural societies

27 (Cadwell, 2014; Cadwell and O’Brien, 2016; O’Brien and Cadwell, 2017). Increased people displacement and economic migrations across the world causes major concerns for migrants' adaptability to disasters in their new contexts. Although displaced populations can be resilient because of their past experiences (Guadagno et al., 2017;

31 Khan and McNamara, 2017; MICIC, 2016), at the same time they can be exposed to new vulnerabilities in their new environments with limited access to information (Puthoopparambil and Parente, 2018). Language plays a role in both cross-boundary and local settings. Local crises in multilingual societies equally have implications for temporary or long-term residents with limited proficiency in the local language - an example: translations into 18 languages were needed after the Grenfell Tower fire. Thus, from indigenous populations to (un)integrated migrants, to tourists or business travellers, any crisis can cascade into multiple, diverse, and interrelated temporal, cultural, linguistic and geographical dimensions (Pescaroli and Alexander, 2015).

40 Consequently, language translation is required. and collecting data from disasters (Mulder et al., 2016) also happen in multilingual environments, where the lingua franca (the English language of international humanitarian institutions) is both a solution and part of the problem. Overreliance on everybody's (degrees of) competence in English delays engaging with the 'perennial issue' of crisis communication among international responders (Crowley and Chan, 2011, p. 24) and with crisis-affected communities (New Zealand Government, 2013). In this article, we make the case for increased attention to language translation in crisis communication. Translation is here intended as linguistic and cultural transfer 
50 from one language into another, be it through oral, signing, written, or multimodal

51 channels. We show how, in spite of some progress, the literature that deals with the multilingual nature of crisis situations is limited in fields where it should thrive, such as in crisis communication and in translation studies. Despite the central role attributed to efficient communication in disaster risk reduction (henceforth DRR), our current ability to plan and deliver multilingual information in crises is in fact hindered by the focus on language needs that is predominantly limited to considering, dealing, or resolving language issues in the response phase. We propose a shift of focus towards considering language translation as part of disaster prevention and management. Embedded in debates on planning, preparedness, training, and mitigation, language translation aligns with the recent call to consider communication of crucial and timely information in

61 crisis management as a human right (Greenwood et al., 2017). Yet, as the cursory evidence on how the multilingual communication issues are studied so far shows this right goes currently unnoticed, or gets very limited attention, at best.

\section{What is Crisis Translation?}

65 Communication mediated by professional and ad-hoc linguists (be they translators or 66 interpreters) is a complex form of communication. Prior to explaining the proposed

67 conceptualisation of crisis translation, it is necessary to scope what is meant by

68 'translation' and 'crisis', as used in this article. We propose a broad conceptualisation of

69 crisis translation as a specific form of communication that overlaps with principles of 70 risk communication (CDC, 2008, 2014; Reynolds and Seeger, 2014) as much as with 71 principles of emergency planning and management (Alexander, 2002; 2016b).

72 Over the last decades, the recognition that any disruptive event has cascading effects

73 has become significant. As issues in multilingual communication exist before, during, and after any emergency or disaster, an awareness of cascading effects over the long- 
term and beyond the geographical location of the event is a conditio sine qua non to consider definitions of crisis that account for the interconnectedness of the 21 st-century world. Pescaroli and Alexander's definition of 'cascading disasters' (2015), which connects crisis as a threatening condition with disasters as triggering events of different magnitude and duration, shapes our definition of crisis. In particular, Pescaroli and

80 Alexander (2015, p. 62) integrate and sharpen the UN Office for Disaster Risk

81 Reduction terminology by emphasizing 'that cascades are events that depend, to some extent, on their context, and thus their diffusion is associated with enduring vulnerabilities'. It is noteworthy, however, that the UN perceives language translation as a matter of 'services'. For instance, the Disaster Assessment and Coordination Field Handbook (UNDAC, 2018) in the workflow of its On-Site Operations Coordination

86 Centre for disaster management includes in one of its checklists for crisis communication "procurement of translation/interpretation services" (UNDAC 2018, p. 17). This positive awareness of need clashes with the reality that such services may exist professionally in very limited scope, translators and interpreters are not trained in

90 the many language pairs that may be required, and local languages, dialects, minority

91 languages, and low/no literacy communities are less served than lingua franca or 'international' languages. The lack of appropriate linguistic and cultural awareness in crisis communication may lead to catastrophic consequences, which could be avoidable

94 and for this reason we position this lack within the 'cascading disaster' paradigm.

95 Problems of translation leading to inappropriate evacuations (e.g. Field, 2017) or

96 cultural presumptions leading to further infection in displaced and local populations in 97 the 2014 Ebola outbreak (e.g. Bastide, 2018) show that inadequate planning for language translation provision leads to vulnerability. 
The UN defines as vulnerabilities 'the conditions determined by physical, social,

100 economic and environmental factors or processes which increase the susceptibility of an

101 individual, a community, assets or systems to the impacts of hazards. ${ }^{\text {i }}$ Vulnerabilities

102 also depend on cultural perceptions of risk and whether cultural backgrounds align with

103 the international (often Anglophone) concepts of preparedness and risk reduction (see

104 discussions in Blaikie et al., 2004; Krüger et al., 2015). Lack of integration, lack of

105 participation, lack of access to information represent vulnerabilities for Culturally and

106 Linguistically Diverse (CALD) communities. Translation would mitigate some of these

107 pre-existing vulnerabilities, but as Grin (2017, p. 156) puts it ' $[\mathrm{t}]$ ranslation sometimes

108 evokes the image of a Cinderella confined to humble domestic chores while her elder

109 sisters, that is, communication strategies like "lingua franca" and second/foreign

110 language learning, enjoy all the attention and visibility'. The consequences of these are

111 highlighted in the recent IFRC World Disasters Report 2018: Speakers of minority languages who are not fluent in the official national language(s) are at a structural disadvantage in many countries. [...] However linguistically diverse the affected population, humanitarian responses are usually coordinated in international lingua francas and delivered in a narrow range of national languages. (IFRC, 2018, p. 103)

117 As a result, language translation rarely, if ever, features among plans to increase

118 resilience but its absence increases the cascading effects of crises. Pescaroli and

119 Alexander's definition of 'cascading disasters' (2015, pp. 64-65) underpins a notion of

120 'crisis' that persuades us that research into translation and its effects on communication

121 in crisis management is much needed. Poor or culturally inappropriate communication

122 undermines trust in responders and institutions. Failure to address effective

123 communication for CALD communities generates further social disruption, one of the

124 cascading effects. This, in turn, risks affecting and endangering respondents who may 
125 deal with crisis-affected populations because their lack of understanding or their cultural

126 mindset make them appear as non-collaborative. Thus, crisis translation considers

127 language barriers in the context of multi-dimensional cascading effects that widen

128 existing vulnerabilities or engender new ones by means of miscommunication.

As mentioned earlier, 'translation' here refers to all modes, oral, written, signed,

130 and multimodal that could be used for communication in preparation and response, as

131 well as for recovery from a crisis. Hence, 'translation' includes the oral task of

132 'interpreting'. For those outside the academic and professional domain of translation,

133 debates about the different skills required from translators and interpreters are largely

134 unknown and 'translation' is the term used generally to mean the transfer of meaning

135 and cultural encodings from one language/cultural system to another regardless of the

136 channel of communication (e.g. the Harvard Humanitarian Initiative heading

137 'translation: the perennial hidden issue' concerns in fact a question of interpreting).

138 Moreover, an individual may act as a translator of written content in one instance and an

139 interpreter of oral content in another. This is especially the case in crisis situations. The

140 term 'translator' is usually reserved in academia and in the translation professions

141 (Gouadec, 2007) for those who are 'qualified' to act through training and/or experience.

142 However, in a crisis situation, a 'translator' might be any person who can mediate

143 between two or more language and culture systems, without specific training or

144 qualifications (Federici and Cadwell, 2018; O'Brien and Cadwell, 2017). A translator

145 might even be a young refugee (see Marlowe and Bogen, 2015; Melandri et al., 2014).

146 This loose definition of a translator is not a comfortable one for those who work in the

147 translation professions or in the related academic discipline. Nonetheless, when people

148 are faced with a crisis, the luxury of a trained professional is often just that - an

149 unattainable luxury. We recognize that translation is carried out by many different 
150 people in crisis situations; that it is sometimes oral, sometimes written, and sometimes

151 highly multimodal; that the translator is sometimes a trained professional and

152 sometimes not, sometimes an adult, sometimes a child, that translators do not just

153 transfer linguistic information, but also act, very importantly, as cultural mediators.

154 Take this state of affairs and add to it the lack of trained translators and interpreters who

155 are available to work in a crisis, the lack of funding for communication, never mind

156 translation, the urgency that is associated with core phases of crises (response and

157 recovery), and the potential power of volunteers, it is necessary to adopt a broad

158 definition of 'translation' and 'translator'.

\section{Growing Recognition of the Need}

160 We do not wish to give the impression that translation is entirely overlooked in

161 commentaries or policies on crisis communication. At the Sendai implementation

162 conference in 2016, translation and interpreting were discussed in the context of

163 capacity building for disaster risk reduction (Aitsi-Selmi et al., 2016). The GDACS

164 (Global Disaster Alert Coordination System $^{\text {ii }}$ ) guidelines for international exchange in

165 disasters mentions translators once, but they are listed in the company of the following

166 information exchange responsibilities of the affected country: 'transport, fuel/lubricants,

167 translators, warehouses, maps, etc. The Sphere Handbook (2018: p. 71), under

168 commitment 6 on information sharing in humanitarian response, includes two explicit

169 communicative obligations: 'Communicate clearly and avoid jargon and colloquialisms,

170 especially when other participants do not speak the same language. Provide interpreters

171 and translators if needed'.

172 Cadwell (2015) and Cadwell and O'Brien (2016) investigate the use and

173 potential of translation technology in crisis situations. Somewhat surprisingly, it was

174 found that industry-standard and commercial translation tools such as translation 
memory, terminology databases, and machine translation (i.e. MT - fully automatic translation) played an insignificant role for foreign nationals affected by the Great East

177 Japan Earthquake. Since then, the potential of translation technology to assist in crisis

178 situations has been growing (see O’Brien - forthcoming - for a discussion). Having

179 crisis terminology online is of course useful, but accessibility in times of crisis for all

180 the potential actors has not been critically appraised and ways of building and sharing

181 translation databases, for example, by and for volunteers goes largely unassessed, as

182 does the utility of such databases for the training of machine translation engines.

184 from the NGO Translators without Borders (TWB). It has played a leading role in

185 having translation recognized and implemented as part of humanitarian aid in the past

186 number of years, including pioneering work to train crisis translators (O'Brien, 2016).

187 Their Words of Relief project aims to translate crisis messages into 15 world languages,

188 build a spider network of diaspora who can translate, and create a crowd-sourced

189 application that connects aid workers and data aggregators in an emergency. In addition,

190 TWB partnered with Microsoft to push forward crucial work in machine translation

191 (Crisis MT, see Lewis, 2010; Lewis et al., 2011) and their operations office in Kenya

192 stimulated a first study on comprehension of translated information about Ebola among

193 Kenyans.

\section{Yet, Translation is Mostly Ignored}

195 In spite of these seedling developments, translation as a facilitator of crisis information

196 is mostly overlooked. In 2018, the 'Multi-Hazard Early Warning System: A Checklist'

197 (WMO, 2018) shows how awareness about cultural and linguistic differences remains

198 very limited. Even though the checklist responds to the purpose of the Sendai

199 Framework for Disaster Risk Reduction 20-15-2030 (UNISDR, 2015) so as to attain 
200 'the substantial reduction of disaster risk and losses in lives, livelihoods and health and

201 in the economic, physical, social, cultural and environmental assets of persons,

202 businesses, communities, and countries,' the checklist remarkably excludes language

203 obstacles to effective communication. Linguistic diversity is the status quo in most

204 countries world-wide. However, 'language' is often conflated with the concept of

205 'culture' and the implicit assumption seems to be that if cultural diversity is noted,

206 translation will somehow happen; many international documents, including influential

207 documents such as this checklist, are redacted in one of the 7 official languages of the

208 UN, whilst 7,111 languages are currently actual use (Ethnologue, 2019) ${ }^{1}$. Yet languages

209 such as Hindi, the $4^{\text {th }}$ largest for native speakers and $3^{\text {rd }}$ largest for overall number, are

210 not included among the official languages. It is tempting to argue that considerations

211 about linguistic diversity recede before prestige and power of lingua francas. Moreover,

212 translation costs money, which may not abound in crisis response. It also requires

213 forward planning. For example, establishing a database of approved translators and

214 interpreters for specific language pairs, knowing their expertise, their availability etc.

215 As a result of these and possibly other factors, the fact that linguistic diversity comes

216 with translation needs in cross-boundary crises remains underestimated.

217 It is unclear who has ownership of provision for effective communication in a

218 language that is understood by the recipients of crisis information. The document

219 dedicated to early-warning signals does not suggest that a specific responder (person or

220 institution) should deal with the logistical difficulties of accommodating language

221 differences when communicating risks with the purpose of mitigating its impact. CALD

222 communities and their needs are listed; they are included in checks for assessment of

\footnotetext{
${ }^{1}$ Source: https://www.ethnologue.com/guides/how-many-languages, accessed: 26 June 2019.
} 
223 'exposure, vulnerabilities, capacities, and risks' (p.10) where the checklist includes a

224 box for 'legislation and cultural norms assessed to identify gaps that may increase

225 vulnerability.' Though cultural diversity is listed, it does not follow automatically that

226 language needs are either included or taken care of, as mentioned above. The focus,

227 rather, seems to be on cultural and behavioral norms, but not on language access.

Further, in the extensive body of literature on crisis or disaster management,

with its intrinsic terminological debates on what disaster management entails (Fischer,

2008; Haddow et al., 2011; Thomas et al., 2013; Wall and Chery, 2011; Waugh, 2007),

or in the charter of humanitarian response of The Sphere Project (2011; as seen some

more commitment appears in the 2018 edition), the common denominator appears to be

233 that multilingual communication issues are considered sporadically, and only recently

234 have they acquired limited visibility. In some of this literature, the strategic importance

235 of communication, or information as aid, is highlighted (Fischer, 2008; Isiolo, 2012;

236 Santos-Hernández and Hearn Morrow, 2013; Seeger, 2006; WHO, 2012). In

237 international and European protocols or roadmaps on crisis or emergency management,

238 recommendations on clear communication with crisis-affected communities form a core

239 element yet they do not mention translation (DG-ECHO, 2013; EC, 2014, 2017). A

240 recent institutional commitment from the United Nations High Commission for

241 Refugees has one formal commitment about access to information - to address

242 migration crises:

Therefore, we need to maintain continuous communication with communities, using languages, formats, and media that are contextually appropriate and accessible for all groups in a community, including children and persons with disabilities. (UNHCR, 2018, p. 8)

247 It is, at best however, a general statement of principle. 

signalled the importance of communicating transparently about disasters (EC, 2014) and recently introduced an economic argument in favor of risk reduction and prevention that applies to considering translation as a tool to better inform and educate for prevention: 'We know that investment in prevention saves lives and livelihoods; it needs therefore efficient targeting to disaster risks' (EC, 2017, section 2). These goals sit alongside the rights-based notion that whatever the status of one's spoken language (Mowbray, 2017), information in a crisis is a fundamental human right (Greenwood et al., 2017; O'Brien et al., 2018).

Some of these commentators have provided evidence of negative consequences when crisis communication does not work, especially when communication is in a second or third language for the crisis-affected communities, or in a language they do not understand at all. The pivotal work, previously mentioned, Disaster Relief 2.0, published by Harvard Humanitarian Initiative (Crowley and Chan, 2011), using the Haiti Earthquake example, argues for increased cooperation and dialogue between humanitarian agencies and the technical and linguistic volunteers spread around the globe who help process the communication generated by the disaster-affected communities. It also called for deeper interactions in future disasters between those responding to and those experiencing a disaster; eight years on and this issue is still relevant as it remains unaddressed (Cook et al., 2016). needs of large-scale humanitarian actions and deployments are rarely voiced, often

270 downplayed and at best indirectly stated.' To provide additional concrete examples,

271 Haddow et al. (2011) in their Introduction to Emergency Management, list five critical assumptions for a successful crisis communications strategy: (1) customer focus; (2) 
273 leadership commitment; (3) the inclusion of communications and planning in operations; (4) situational awareness; and (5) media partnership. The audience and customers of crisis information are listed as the general public, victims, the business community, media, elected officials, community officials and volunteer groups (i.e. a

277 diverse group). It cannot be assumed that all these people share equal competencies in 278 the same language, so translation is a necessity. Yet, nowhere is translation mentioned 279 in this volume.

The DG ECHO Disaster Risk Reduction Policy Document discusses the importance of inclusive information and communication and mentions in particular that information should be 'accessible for all' (DG-ECHO, 2013, p. 41). This document also mentions strengthening resilience through timely exchange of information. However, making information accessible by either simplifying it for those with limited proficiency in a lingua franca, or translating it is only mentioned very briefly ('briefing of colleagues and translation in practice').

In his discussion on lessons learned from previous disasters, Fischer (2008, p. 217) notes that instructions for obtaining medical assistance and subsistence supplies as well as instructions for an evacuation or a quarantine are more likely to be responded to if they are frequently repeated, articulated clearly and with specificity. All too often emergency personnel assume that because the information was disseminated, the intended recipients have received it, understood it, and responded to it in the desired fashion. Nothing could be further from the truth.

296 fails to note that, for communication to be effective, it does not only have to meet the requirements listed above, but should be delivered in a language that is comprehended by those who need that communication. Retention, understanding, and desire for 
299 information in specific modes or formats by affected populations are excluded from this

300 equation, with the risk of one-directional forms of communication (for an illustration,

301 see O’Brien and Cadwell, 2017).

In his 2006 article on best practices in crisis communication, Seeger lists ten

best practices on crisis communication generated from research literature. Due to space constraints, we do not list them all here, but emphasize practice number (8), given its significance for ethical crisis communication: communicate with compassion, concern, and empathy. None of the 'best practices', not even (8), recognize the role of multilingual communication through translation.

Access to compassionate speakers of one's language represented a powerful resource for refugees caught in the aftermath of the 2010 and 2011 earthquakes in New

310 Zealand (Christchurch and Canterbury), but it was acknowledged that improvements in

311 communicating with culturally and linguistically diverse communities was required

312 (New Zealand Government, 2013). As a final example, even Santos Hernández and

313 Morrow (2013) who focus on language and literacy as factors in successful crisis

314 communication, acknowledge the importance of readability using typical measures such

315 as SMOG and Flesch-Kincaid, but fail to mention translation or interpreting. In

316 summary, there are ample examples of a considerable lacuna for the role and need for

317 translation in academic, governmental, and non-governmental discourse on crisis

318 communication.

\section{Crisis Translation and Emergency Planning}

320 We intend to demonstrate that in the context of DRR and crisis management alike,

321 additional focus on the language barrier would greatly contribute to community-led

322 initiatives to mitigate risks (Gaillard, 2010; Mercer et al., 2012; Shaw, 2012; Tabatabaei et al., 2013). Language translation is a significant problem in the response phase of 
324 disasters, as deploying language specialists in combinations that are difficult to predict

325 in advance is an expensive and logistically challenging task; as we mentioned previously, interpreters and translators for the needed language combinations may not

327 be available, fully trained, or even exist. It is likely to remain an impossible task to

328 complete if the focus remains only on the response phase. In order to deploy interpreters

329 or provide information in languages that reach the affected communities, translators and 330 interpreters must be available. Professional translators are rare in many language 331 combinations, so bilingual staff of NGOs double up as translators and interpreters. This 332 role is frequently imposed on such staff, on top of their existing workload, and without 333 training or support. Also, translators and interpreters may even be affected themselves 334 by whatever crisis is ongoing.

335 Embedding translation into communication strategies within emergency 336 planning is part of the solution, like any other element that can be considered and 337 included in emergency plans as part of the "the process of preparing systematically for 338 future contingencies, including major incidents and disasters' (Alexander, 2016b, p. 2).

339 This could involve pre-translated, pre-subtitled, pre-audio described materials in the 340 languages understood by the local communities to be part of early actions. To achieve 341 this, language translation needs to be part of pre-crisis emergency plans that will include 342 the development of resources to enable affected-communities to interact with disaster 343 managers and humanitarian organization. The "so-called "disaster cycle" refers to the

344 phases of resilience building, preparation, emergency response, recovery, and

345 reconstruction' (Alexander, 2016b, p. 23). Our contention is that translation can play an 346 important role towards preparedness.

347 Including translation as a component in emergency planning would have 348 multiple benefits. With increased access to timely and accurate information in a 
349 language that can be (better) understood, lives and well-being can be protected.

350 Moreover, the considerable economic costs of dealing with crises could be reduced. The

351 EU H2020 Work Programme noted that the environmental and socio-economic impact

352 of disasters and crime and terrorism on the population amounts to average annual losses

353 of roughly $25 \%$ of the global GDP and $5 \%$ of the Union's GDP, respectively. According

354 to the UNISDR, the 2013 central European floods alone resulted in losses of US\$18

355 billion. In the foreword to the World Atlas of Natural Disaster Risk (Shi and Kasperson,

356 2015), the then UN Special Representative of the Secretary General for Disaster Risk

357 Reduction, Mrs Margareta Wahlström, stated that economic losses as a result of

358 disasters continue to rise. It is estimated that in the past three years, losses due to

359 disasters have exceeded $\$ 100$ billion. In 2005, the UK Department for International

360 Development put forward a policy briefing document arguing that investment in risk

361 reduction is more cost-effective than just response actions when crises occur (White et

362 al. 2005). To shift from managing disaster to the proactive prevention of risk, with

363 possible reductions in the cost of disasters, multilingual communication needs to take its

364 proper place in the list that normally includes supplies, medicine, infrastructure and

365 technology.

366 Steps can be taken to incorporate translation into emergency planning. A logical

367 starting point is to ensure that it is a concrete and explicit part of emergency response

368 policy. The lack of reference to translation in policy or guideline documents is

369 unsurprising, given that there is not even agreement in policy documents on what core

370 terms such as vulnerability, capacity, and resilience mean. Gaillard (2010) discusses

371 how these core terms in DRR are often interpreted differently, depending on whether

372 the policy makers are active in the domain of climate change, development, or DRR. He

373 believes that huge efforts are required to close the gap between these domains as well as 
374 between practitioners and scientists. Given conceptual differences at that level, it is not

375 hard to understand that translation hardly figures in policies relating to disasters and

376 crises. Expert terminology and the lack of preparedness in sourcing specialist translators

377 can be a deadly combination. An example of language needs from the local community

378 is given by Field (2017, p. 340) through her discussions with local groups. The failure

379 to evacuate appropriate regions before the landfall of Typhon Yolanda in the

380 Philippines partially rests on a lack of appropriate translation based on local cultural

381 needs: 'while the two are scientifically different phenomena, it was acknowledged that

382 had the threat of the storm surge been likened to that of a tsunami (for a coastal

383 population hit by a wave, the impact would be similar), the coastal regions would have

384 seen higher evacuation rates, particularly due to familiarity with the 2004 Indian Ocean

385 tsunami and the more recent 2011 tsunami in Japan'.

386 There is an urgency to identify best practices and to provide new insights for, or

387 indeed create, recommendations for crisis translation policy for national, European, and

388 international agencies that regularly work across borders and across languages, with a

389 view to reversing inequalities across language communities and promoting fairness of

390 access to information. This approach will be especially important in the context of new

391 migration patterns and policy requirements for Europe. Crisis communication literature

392 emphasizes the difficulties when trying to communicate with those who are the most

393 vulnerable, e.g. the elderly, disabled, children, or those with low literacy levels. Dealing

394 adequately with these challenges must be within the scope of crisis translation into the

395 future, when, in many societies with migrant populations, first generation migrants will

396 represent large communities in the care homes and their linguistic skills may not meet

397 their communicative needs. 
399 NHS, 2015; Cabinet Office, 2012) provide for language provision for limited-

400 proficiency speakers, but more empirical data on the ways in which translation is

401 understood in these policies is required (O'Brien et al., 2018), not to mention how

402 policies are implemented.

404 disasters, we opt for an activist approach. Viewing the definition from the point of view

405 of emergency planning, research into crisis translation needs to explore the roles of

406 language in all the phases of a disaster, including during the 'normal' phase in which

407 resilience is built up. Alexander (2016a, p. 14), discussing emergency planning, reminds

408 the reader that '[a] crisis is a sudden, intrusive interruption of normal conditions with

409 potentially adverse consequences. "Normality" is defined here as the average of

410 conditions over a protracted period in which things function acceptably'. If CALD

411 communities are being supported by intercultural mediators (Belpiede, 1999; Casadei

412 and Franceschetti, 2009), interpreters, or community translators (Taibi, 2011; Taibi and

413 Ozolins, 2016) to access information in normal conditions, surely this confirms that

414 such needs will persist, in fact be exacerbated, in crisis situations. We suggest inverting

415 the research priorities, so that by building up data, resources, and technology, these can

416 be better deployed in the response and recovery phases. Just as other specialist skills

417 receive training to operate in emergencies, linguists ought to receive training to provide

418 support in crises and to create valuable expertise in handling language needs by being

419 embedded in crisis management practices. Translation, interpreting, cultural mediation,

420 and relationships between different language communities that enhance effective

421 communication in crisis connecting linguistic sub-groups to the broader society need to

422 be considered as part of the preventive measures that prepare residents for emergency 
response (Federici, 2016). A good example is the initiative described by Clerveux et al.

424 (2010) where a Disaster Awareness Game (DAG) is developed to help increase hazard awareness among school children in the Caribbean Community and Common Market area. This multicultural area demands a multilinguistic approach to risk communication.

427 Clerveux et al. (ibid.) argue that children are an appropriate target for the DAG because 428 it is an investment in future disaster preparedness, but also because children of 429 immigrant families are a conduit of information between school and home. They show 430 awareness of the need for accessibility of the game, mentioning simple language and the 431 potential for translation. Nevertheless, the game itself, as represented in the paper, is in

432 English, which still falls short of truly serving multilinguistic needs. Another good 433 example is discussed in Shackleton (2018); New Zealand Red Cross worked with 434 members of CALD offering them translation training in order to contribute to a project 435 to increase awareness of emergencies affecting the Wellington region. In this project, 436 under-resourced language combinations saw CALD members develop a basic 437 understanding of translation and linguistic resources to describe natural hazards in the 438 local area through languages other than New Zealand's main languages (English and Te

439 Reo Maori). These are good illustrations of how translation can be embedded in 440 practices of risk reduction; the CALD members involved in the project would not be 441 professional interpreters in case of a response, but they could contribute to circulating 442 information in translations (written texts, texts written to be read, radio or TV 443 broadcasts) to allow CALD communities to attain information in a language they 444 understand and in a format accessible to them. The example has limitations, however, as 445 it does not entail a feedback loop seeking to find out from the CALD communities what 446 information they would like to have and which formats are most appropriate. 
Written, oral, and multimodal communication channels are used at different stages of a crisis, with different audiences. Only early phases of crises automatically call

449 for oral interpreting; preparedness activities and reconstruction phases after a crisis are more likely to call for translation, if there is an awareness of language needs. These are broad differentiations: empirical data to identify how municipal, regional, or national-

452 level policies connect CALD needs with emergency planning is required. The data need to have a cross-border as well as a local dimension to make sense of the needs of CALD communities; often the data on ethnographic and linguistic background may be collected for other reasons (census, electoral rolls) and these data could help identify existing needs and create the premises (databases, leaflets, technological resources) to develop language support for the time when it is needed. Data accuracy, assessment of real language competences, distance between rural and urban needs, and budget are among the obvious obstacles to developing crisis translation resources. However, this complexity can no longer be a sufficient justification for a reactive mode to deal with

461 the language barrier, because cross-referencing such data with other well-known

462 datasets on hazardscapes, risks, and models derived from statistical data can be done as

463 part of disaster prevention measures. Interpolating these existing data would create more valuable resources than what can be put together in the middle of a response.

The role of translation in recovery, reconstruction, and preparation phases

(intended as learning from activities just completed during the response phase) has not been studied much either. This point begins to be appreciated also in the crisis communication literature: relief organizations, and other actors involved in cross-cultural crises and communication have almost no evidence-based and well-established guidelines they can use to organize or coordinate international crisis communication or to 
develop culture-sensitive crisis communication strategies or messages (instruction, adjusting information, etc.). (Schwarz et al., 2016, p. 6)

475 Taking the most cynical of arguments, even if all the preparations are never going to be 476 needed, the benefits of involving CALD communities in preparedness strategies would 477 at the very least lead to more inclusive societies.

\section{Conclusions}

479 Crisis translation should be viewed from the point of view of reducing vulnerabilities and providing efficient communication that would reduce costs if/when a crisis erupts.

481 Feeble yet slowly-growing is the voice of cost-effectiveness of investing in 482 preparedness, as in the Communication of the European Commission of 23 November 2017:

Evidence of failings in crisis communication is plentiful and usually categorised under 'issues of communication'; reasons for avoiding these failings are compelling (Greenwood et al., 2017), translation is considered as a 'perennial hidden issue'

491 (Crowley and Chan, 2011, p. 24; IFRC 2018, p. 103), yet its inclusion in emergency

492 planning (and studies thereof) remain minimal and alternatives of plain or clear

493 language are still offered as adequate solutions, but are blind to the needs of those who 494 have very limited or no competence in the 'language' in question in the first instance 495 (see Strayhorn et al. 2012, for example), who cannot read, see, or hear. 
situations. We need to understand authentic training needs to support linguists (intended

499 here as anybody with some knowledge of more than one language) who may need,

500 want, or be co-opted to operate as translators in rare-language combinations when they

501 are not professionally trained. We need to identify beforehand the needs of local

502 populations in relation to existing capabilities to deal with multilingual contexts and to

503 identify ways of developing additional capabilities. We need to seek a better use for the

504 skills, technologies, and existing data on translation to be used in planned and

505 sophisticated ways rather than as afterthoughts at the moment of dire need. Crisis

506 Translation, as we propose in this article, is a catalyst research area to develop a

507 holistic, multidisciplinary, and comprehensive understanding of the role of

508 communication in multilingual crisis situations, so as to better address the necessity for

509 accommodating language needs in crisis situations, thus lessening the impact of the

510 language barrier in cascading crises.

511

512

Acknowledgement. [ANONYMISED FOR PEER REVIEW].

513

514 References

515 Aitsi-Selmi, A., Murray, V., Wannous, C., Dickinson, C., Johnston, D., Kawasaki, A., 516 Stevance, A.S., and Yeung, T. (2016), "Reflections on a science and technology agenda for 21st century disaster risk reduction", International Journal of Disaster Risk Science, Vol. 7 No. 1, 1-29.

Alexander, D. E. (2002), Principles of Emergency Planning and Management, Oxford University Press, Oxford; New York, NY.

Alexander, D. E. (2016a), How to Write an Emergency Plan, Dunedin Academic Press, Edinburgh.

523 Alexander, D. E. (2016b), "Disaster and emergency planning for preparedness, response, and recovery", in Cutter, S. L. (Ed.), Oxford Research Encyclopedia 
Natural Hazard Science, Oxford University Press, Oxford; New York, NY, pp. 1-20.

527

528

529

530

531

532

533

534

535

536

537

538

539

540

541

542

543

544

545

546

547

548

549

550

551

552

553

554

555

556

557

Bastide, L. (2018), "Crisis Communication During the Ebola Outbreak in West Africa: The Paradoxes of Decontextualized Contextualization." In Bourrier, M. and C. Bieder (Eds.), Risk Communication for the Future, Cham: Springer, pp. 95-108. Belpiede, A. (1999), "La professione di mediatore culturale in ambito sociale", Prospettive Sociali e Sanitarie, Vol. 2 No. 99, pp. 11-14.

Blaikie, P., Cannon, T., Davis, I., and Wisner, B. (2004), At Risk. Natural Hazards, People's Vulnerability and Disasters (2nd ed.), Routledge: New York.

Cabinet Office (2012), "Emergency preparedness: Guidance on part 1 of the Civil Contingencies Act 2004, its associated regulations and non-statutory arrangements", London: Crown, available at: https://www.gov.uk/governmen t/publications/emergency-preparedness (accessed 21 November 2018).

Cadwell, P. (2014), "Translation and interpreting needs in the Great East Japan Earthquake of 2011”, paper presented at the Man versus Machine Conference, Proceedings of the XXth FIT World Congress (Vol. II), pp. 752-760.

Cadwell, P. (2015), “A place for translation technologies in disaster settings: The case of the 2011 Great East Japan Earthquake”, In O’Hagan, M. and Q. Zhang (Eds.), Conflict and Communication: A Changing Asia in a Globalising World, EHV Academic Press: Bremen, pp. 248-282.

Cadwell, P., and O’Brien, S. (2016), "Language, culture, and translation in disaster ICT: An ecosystemic model of understanding", Perspectives. Studies in Translation Theory and Practice, Vol. 24 No. 4, pp. 557-575.

Casadei, S., and Franceschetti, M. (2009), "Il mediatore culturale in sei Paesi europei”, Rome: ISFOL, available at: http://archivio.isfol.it/DocEditor/test/File/2009/Strumenti_Isfol/Il_Mediatore_cu lturale_in_sei_Paesi_europei.pdf (accessed 21 November 2018).

CDC. (2008), “Crisis, emergency and risk communication”, Atlanta, GA: Centers for Disease Control and Prevention, available at: https://emergency.cdc.gov/cerc/index.asp (accessed 21 November 2018).

Clerveaux, V., Spence, B. and Katada, T. (2010), "Promoting disaster awareness in multicultural societies: the DAG approach", Disaster Prevention and Management: An International Journal, Vol. 19 No. 2, pp.199-218. 
Cook, A. D., Shrestha, M., and Htet, Z. B. (2016), "International response to 2015 Nepal earthquake: Lessons and observations", available at: https://www.rsis.edu.sg/wpcontent/uploads/2016/10/NTS_Report_5_Nepal_final_revised_Oct.pdf (accessed 21 November 2018).

Coombs, W. T. (2004), "Impact of past crises on current crisis communication: Insights from situational crisis communication theory", The Journal of Business Communication, Vol. 41 No. 3, pp. 265-289.

Crouse Quinn, S. (2008), “Crisis and emergency risk communication in a pandemic: a model for building capacity and resilience of minority communities", Health Promotion Practice, Vol. 9 No. 4, pp. 18S-25S.

Crowley, J., and Chan, J. (2011), “Disaster Relief 2.0: The future of Information Sharing in Humanitarian Emergencies", Vodafone Foundation: Washington, DC and Berkshire, UK.

DG-ECHO (2013), "Disaster risk reduction. Increasing resilience by reducing disaster risk in humanitarian action", available at: http://ec.europa.eu/echo/ files/policies/prevention_preparedness/DRR_thematic_policy_doc.pdf (accessed 21 November 2018).

EC (2014), "General guidelines for operational priorities on humanitarian aid in 2015", available at: http://ec.europa.eu/transparency/regdoc/?fuseaction=list\&coteId=10102\&year=2 014\&number $=345 \&$ language $=E N$ (accessed 21 November 2018).

EC. (2017), "Strengthening EU disaster management: rescEU solidarity with responsibility. Available at: http://ec.europa.eu/transparency/regdoc/?fuseaction=list\&n=10\&adv=0\&coteId= 1 \&year $=2017 \&$ number $=773 \&$ version $=F \&$ dateFrom $=\&$ dateTo $=\&$ serviceId $=\&$ do

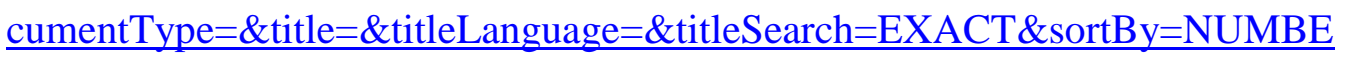
R\&sortOrder=DESC2017 (accessed: 21 November 2018).

Federici, F. M. (2016), “Introduction: A state of emergency for crisis communication”, in Federici, F. M. (Ed.), Mediating Emergencies and Conflicts. Frontline Translating and Interpreting, Palgrave Macmillan, New York, NY, pp. 1-29. Federici, F. M. and Cadwell, P. (2018), “Training citizen translators: Red Cross translation needs and the delivery of a bespoke training on the fundamentals of 
translation", in Tesseur, W. (Ed.), Translation in Non-governmental Organisations. Special issue of Translation Spaces, Vol. 7 No. 1, pp. 20-43.

593

594

595

596

597

598

599

600

601

602

603

604

605

606

607

608

609

610

611

612

613

614

615

616

617

618

619

620

621

622

623

624

Field, J. (2017), "What is appropriate and relevant assistance after a disaster? Accounting for culture(s) in the response to Typhoon Haiyan/Yolanda." International Journal of Disaster Risk Reduction, Vol. 22, pp. 335-344.

FEMA. (2016), “Language access plan”, available at: https://www.dhs.gov/sites/default/files/publications/FEMA\%20Language\%20A ccess\%20Plan.pdf (accessed 21 November 2018).

Fischer, H. W. (2008), Response to Disaster: Fact versus Fiction and its Perpetuation: The Sociology of Disaster (3rd ed.). University Press of America, Lanham, MD. Gaillard, J.-C. (2010), "Vulnerability, capacity and resilience: perspectives for climate and development policy", Journal of International Development, Vol. 22 No. 2 , pp. 218-232.

Glade, T., and Alexander, D. E. (2016), "Classification of natural disasters”, in Encyclopedia of Natural Hazards, Springer, Berlin, pp. 78-82.

Gouadec, D. (2007), Translation as a Profession, John Benjamins Publishing, Amsterdam and Philadelphia, PA.

Greenwood, F., Howarth, C., Poole, D. E., Raymond, N. R., and Scarnecchia, D. P. (2017), "The signal code: A human rights approach to information during crisis”, Harvard Humanitarian Initiative: Cambridge, MA, available at: https://hhi.harvard.edu/publications/signal-code-ethical-obligationshumanitarian-information-activities (accessed 21 November 2018).

Grin, F. (2017), “Translation and language policy in the dynamics of multilingualism”, International Journal of the Sociology of Language, Vol. 243, pp. 155-181.

Guadagno, L., Fuhrer, M., and Twigg, J. (2017), Migrants in Disaster Risk Reduction: Practices for Inclusion, IOM, Geneva and Strasbourg Cedex, available at: https://publications.iom.int/books/migrants-disaster-risk-reduction-practicesinclusion (accessed 21 November 2018).

Haddow, G. D., Bullock, J. A., and Coppola, D. P. (2011), Introduction to Emergency Management (4th ed.), Butterworth Heinemann, Burlington, MA.

Howe, A. W., Jennex, M. E., Bressler, G. H., and Frost, E. G. (2013), “Exercise24: Using Social Media for Crisis Response”, in Jennex, M. E. (Ed.), Using Social and Information Technologies for Disaster and Crisis Management, IGI Global, Hershey PA, pp. 232-250. 
IFRC. (2018), World Disasters Report 2018. Leaving no one behind, International Federation of Red Cross and Red Crescent Societies, Geneva, available at:: https://media.ifrc.org/ifrc/wp-content/uploads/sites/5/2018/10/B-WDR-2018EN-LR.pdf (accessed 21 November 2018).

Isiolo, I. A. (2012), “A learning review of the pilot communications project”, available at: http://reliefweb.int/sites/reliefweb.int/files/resources/infoasaidactionaid_isiolo-learningreview032012_2.pdf (accessed 21 November 2018).

Khan, K., and McNamara, T. (2017), “Citizenship, immigration laws, and language”, in Canagarajah, S. (Ed.), The Routledge Handbook of Migration and Language Routledge, New York, NY, pp. 451-467.

Krüger, F., Bankoff, G., Cannon, T., Orlowski, B., and Schipper, E. L. F. (2015), Cultures and Disasters: Understanding Cultural Framings in Disaster Risk Reduction. Routledge, New York, NY.

Marlowe, J., and Bogen, R. (2015), "Young people from refugee backgrounds as a resource for disaster risk reduction”, International Journal of Disaster Risk Reduction, Vol. 14, pp. 125-131.

Melandri, E., Carbonari, L., and Ricci, A. (2014), La qualifica del mediatore interculturale. Contributi per il suo inserimento nel futuro sistema nazione di certificazione delle competenze, ISFOL, Rome.

Mercer, J., Gaillard, J.-C., Crowley, K., Shannon, R., Alexander, B., Day, S., and Becker, J. (2012), "Culture and disaster risk reduction: Lessons and opportunities", Environmental Hazards, Vol. 11 No. 2, pp. 74-95.

MICIC. (2016), Guidelines to protect migrants in countries experiencing conflict or natural disaster. MICIC, Geneva, available at: https://micicinitiative.iom.int/sites/default/files/document/micic_guidelines_engl ish_web_13_09_2016.pdf (accessed 21 November 2018).

Moser-Mercer, B., Kherbiche, L., and Class, B. (2014), “Interpreting conflict: Training challenges in humanitarian field interpreting", Journal of Human Rights Practice, Vol. 6 No. 1, pp. 140-158.

Mowbray, J. (2017), “Translation as marginalisation? International law, translation and the status of linguistic minorities", in González Núñez, G. and Meylaerts, R. (Eds), Translation and Public Policy: Interdisciplinary Perspectives and Case Studies, Routledge, New York, NY, pp. 32-57. 
Mulder, F., Ferguson, J., Groenewegen, P., Boersma, K., and Wolbers, J. (2016), "Questioning big data: Crowdsourcing crisis data towards an inclusive humanitarian response", Big Data and Society, Vol. 3 No. 2, pp. 1-13.

NHS England (2015), "Emergency preparedness, resilience and response framework", available at: https://www.england.nhs.uk/ourwork/eprr/ (accessed 21 November 2018).

O'Brien, S. (2016), “Training translators for crisis communication: Translators without Borders as an example", in Federici, F. M. (Ed.), Mediating Emergencies and Conflicts. Frontline Translating and Interpreting, Palgrave Macmillan, New York, NY, pp. 85-111.

O’Brien, S. (forthcoming), “Translation technology and disaster management”, in O’Hagan, M. (Ed.), The Routledge Handbook of Translation Technology. Routledge, New York, NY.

O'Brien, S., and Cadwell, P. (2017), "Translation facilitates comprehension of healthrelated crisis information: Kenya as an example” Journal of Specialised Translation, Vol. 28, pp. 23-51.

O'Brien, S., Federici, F. M., Cadwell, P., Marlowe, J., and Gerber, B. (2018), "Language translation during disaster: A comparative analysis of five national approaches", International Journal of Disaster Risk Reduction, Vol. 31, pp. 627636.

Pescaroli, G., and Alexander, D. E. (2015), “A definition of cascading disasters and cascading effects: Going beyond the ‘toppling dominos' metaphor”, planet @ risk, Vol. 3 No. 1, doi:https://planet-risk.org/index.php/pr/article/view/208.

Puthoopparambil, S. J., \& Parente, P. (2018), Report on the health of refugees and migrants in the WHO European Region: no public health without refugee and migrant health (2018), Copenhagen; Geneva: WHO Regional Office for Europe, available at: https://apps.who.int/iris/bitstream/handle/10665/311347/978928 9053846-eng.pdf?sequence=1\&isAllowed=y\&ua=1 (accessed: 26 June 2019).

Reynolds, B., and Seeger, M. W. (2005), "Crisis and emergency risk communication as an integrative model”, Journal of Health Communication, Vol. 10 No. 1, pp. 4355.

Reynolds, B., and Seeger, M. W. (2014), "Crisis and emergency risk communication", Centers for Disease Control and Prevention, Atlanta, GA, available at: 
691

692

693

694

695

696

697

698

699

700

701

702

703

704

705

706

707

708

709

710

711

712

713

714

715

716

717

718

719

720

721

722

723

https://emergency.cdc.gov/cerc/resources/pdf/cerc_2014edition.pdf (accessed: 26 June 2019).

Santos-Hernández, J. M., and Hearn Morrow, B. (2013), "Language and literacy”, in Thomas, D. S. K., Phillips, B. D., Lovekamp, W. E. and A. Fothergill (Eds), Social Vulnerability to Disasters (2nd ed.) CRC Press, Boca Raton and New York, NY, pp. 265-280.

Schwarz, A., Seeger, M. W., and Auer, C. (2016), "Significance and structure of international risk and crisis communication research - Toward an integrative approach", in Schwarz, A., Seeger, M.W., and Auer, C. (Eds), The Handbook of International Crisis Communication Research, John Wiley and Sons, Oxford and Malden, MA, pp. 1-10.

Seeger, M. W. (2006), "Best practices in crisis communication: An expert panel process" Journal of Applied Communication Research, Vol. 34 No. 3, pp. 232244.

Shackleton, J. (2018), "Preparedness in diverse communities: Citizen translation for community engagement. Paper presented at the Understanding Risk, Risk Reduction, Consequences and Forecasting Track." Proceedings of the National Academy of Sciences, Wellington, New Zealand, available at: http://idl.iscram.or g/files/jamieshackleton/2018/1655 JamieShackleton2018.pdf (accessed: 26 June 2019).

Shaw, R. (Ed.) (2012), Community Based Disaster Risk Reduction. Emerald Group Publishing, Bingley, UK.

Shi, P., and Kasperson, R. (Eds.) (2015), World Atlas of Natural Disaster Risk. Springer, Heidelberg.

Steelman, T. A., and McCaffrey, S. (2013), "Best practices in risk and crisis communication: Implications for natural hazards management", Natural Hazards, Vol. 65 No. 1, pp. 683-705.

Strayhorn, T., Dasmohapatra, S., Tilotta, D. and Mitchell, P. (2012), "Effectiveness of educational tools for hurricane resilience in homes", Disaster Prevention and Management: An International Journal, Vol. 21 No. 4, pp. 433-444, https://doi.org/10.1108/09653561211256143.

Tabatabaei, F., Nasserzadeh, S. M. R., Yates, S., Akhgar, B., Lockley, E., and Fortune, D. (2013), "From local to global: Community-based policing and national 
security", in Akhgar, B. and Yates, S. (Eds.), Strategic Intelligence Management, Amsterdam, Butterworth-Heinemann, pp. 85-92.

Taibi, M. (2011), "Public service translation”, in Malmkjær, K. and Windle, K. (Eds.), The Oxford Handbook of Translation Studies, Oxford University Press, Oxford and New York, NY, pp. 214 -227.

Taibi, M., and Ozolins, U. (2016), "Community translation: Definitions, characteristics and status quo", in Taibi, M. and Ozolins, U. (Eds.), Community Translation Bloomsbury Academic, London, pp. 7-28.

The Sphere Project. (2011), Humanitarian Charter and Minimum Standards in Humanitarian Response (2nd ed.), The Sphere Project, London and Washington, DC.

The Sphere Project. (2018), The Sphere Project: Humanitarian charter and minimum standards disaster response (3rd ed.), The Sphere Project, London and Washington, DC.

Thomas, D. S. K., Phillips, B. D., Lovekamp, W. E., and Fothergill, A. (Eds.) (2013), Social Vulnerability to Disasters (2nd ed.), CRC Press, Boca Raton.

UNDAC. (2018), United Nations Disaster Assessment and Coordination (UNDAC) Field Handbook (7th edition ed.), Geneva: UNOCHA, available at: https://reliefweb.int/report/world/un-disaster-assessment-and-coordinationundac-field-handbook-7th-edition-2018 (accessed: 26 June 2019).

UNHCR. (2018), Policy on Age, Gender, and Diversity (UNHCRlHCP/2018/1), available at: http://www.unhcr.org/5aa13c0c7.pdf\#zoom=95 (accessed: 21 November 2018).

UNISDR. (2015), Sendai Framework for Disaster Risk Reduction 2015 - 2030, available at: http://www.unisdr.org/files/43291_sendaiframeworkfordr ren.pdf (accessed: 21 November 2018).

Wall, I., and Chery, Y. G. (2011), Ann Kite Yo Pale: Let Them Speak: Best Practice and Lessons Learned in Communication with Disaster Affected Communities: Haiti 2010, available at: https://reliefweb.int/sites/reliefweb.int/files/resources/IAA_Haiti_2010_0.pdf (accessed: 21 November 2018).

Waugh, W. (2007), "Local emergency management in the post-9/11 world", in Waugh, W. and Tierney, K. (Eds.), Emergency Management: Principles and Practice for Local Government, ICMA Press, Washington, pp. 11-23. 
WHO. (2012), Toolkit for Assessing Health-System Capacity for Crisis Management Part 1. User Manual, available at: http://www.euro.who.int/_data/assets/pdf_file/0008/157886/e96187.pdf (accessed: 21 November 2018).

White, P., Pelling, M., Sen, K., Seddon, D., Russell, S., and R. Few. (2005), Disaster Risk Reduction: A Development Concern, DfID, London, available at: https://www.preventionweb.net/files/1070_drrscopingstudy.pdf (accessed: 21 November 2018).

WMO. (2018), Multi-hazard Early Warning Systems: A Checklist. UN World Meteorological Organization, Geneva.

New Zealand Government (2013), Including Culturally and Linguistically Diverse (CALD) Communities, available at: https://www.civildefence.govt.nz/assets/Uploads/publications/is-12-13including-cald-communities.pdf (accessed 21 November 2018).

${ }^{i}$ See UNISDR, https://www.unisdr.org/we/inform/terminology. Accessed 21 November 2018. ${ }^{i i}$ See http://www.gdacs.org. Accessed 21 November 2018. 